\title{
Dossiê Minorias Religiosas: IDENTIDADE E POLÍTICA EM MOVIMENTO
}





\title{
$\longrightarrow$ AMPO EVANGÉLICO Y SOCIEDAD CIVIL: SOBRE LOS PROCESOS DE MINORITIZACIÓN Y EL DESPLAZAMIENTO DE MATRICES ANALÍTICAS
}

\author{
Nicolás Panotto \\ Universidad Arturo Prat \\ Santiago - Chile \\ Orcid: 0000-0002-0513-7175
}

\section{Lo público, lo civil y las identidades religiosas}

Lo que pretendemos en este artículo es proponer algunos ejes de análisis a partir de las mutaciones en torno a los modos de incidencia presentes en ciertos grupos evangélicos, desde su presencia en la sociedad civil y, más concretamente, en su articulación con organizaciones de sociedad civil (OSC). Sus acciones dan cuenta de las transformaciones en el escenario público (tanto local como nacional, regional y global) y, con ello, de la necesidad de nuevas categorizaciones de estudio. Para ello, debemos partir desde la consideración de un conjunto de mutaciones que se están gestando principalmente en tres ámbitos: la comprensión del espacio público, la definición de lo político y el lugar de las dinámicas globales.

Con respecto a la noción de espacio público, es necesario hacernos eco de diversos abordajes (Lefort 1990; Rancière 1996, 2007, 2010; Laclau y Mouffe 2006; AAVV 2010) que cuestionan la visión institucionalista o Estado-céntrica, que pregona extendidamente, en muchos espacios académicos y políticos, principalmente de cuño liberal. Esa visión comprende lo público como un espacio de gestión en torno a los intereses colectivos, donde existen ciertos actores privilegiados que ejercen dicha tarea (principalmente la "clase política" interviniente en la burocracia estatal) y 
donde reside una "razón pública" (Habermas 2009) como marco simbólico-discursivo que encarrila todo tipo de deliberación social "neutral" entre los diversos agentes que lo conforman. Según esa visión, estos agentes, más allá de su particularidad identitaria, deben "ceder" frente a dicho conjunto normativo de relacionamiento, dejando de lado todo tipo de marco distintivo que resalte su particularidad, frente a los términos consensuados como estrictamente "políticos" (ej.: el uso de la Biblia para la deliberación pública).

Estas visiones han sido cuestionadas por varios autores/as que plantean que la institucionalidad del espacio público no remite al Estado o a los partidos como agentes predilectos, sino a un conjunto mucho más amplio de organizaciones, grupos y movimientos, que están por "fuera" de la institucionalidad estatal, aunque no por ello desconectadas, sino presionando sus fronteras a partir de demandas particulares (Laclau 2000). De aquí que lo público deja de ser un espacio de gestión administrada por una jerarquía selecta o votada tras elecciones, para pasar a ser un locus de disputa de sentidos, donde intervienen un conjunto mucho mayor de representaciones que litigan por la noción de "lo común" (Butler, Spivak 2009; Rancière 1996, 2007, 2010).

De esta manera, proponemos pasar de una visión institucionalista a una sociocultural y hermenéutica, donde lo público se entienda como un espacio de encuentro y tensión entre interpretaciones de la realidad, cuyas concreciones históricas se traslucen en un conglomerado heterogéneo y parcial de acciones, institucionalizaciones y proyectos, desde tipos de articulación entre OSC hasta formas de gobierno y políticas sociales. En otras palabras, el sentido de lo público remite a las nociones de pluralidad, intersubjetividad, diálogo y reconocimiento mutuo como dimensiones constitutivas.

"Lo político" deja de ser una tarea en manos de un conjunto de especialistas, para pasar a ser una dimensión constitutiva de toda la sociedad, y aquí nos es útil la distinción que hace Chantal Mouffe (2007:16) entre lo político y la política: “... concibo 'lo político' como la dimensión de antagonismo que considero constitutiva de las sociedades humanas, mientras que entiendo a 'la política' como el conjunto de prácticas e instituciones a través de las cuales se crea determinado orden, organizando la coexistencia humana en el contexto de la conflictividad derivada de lo político". Esta diferenciación nos permite no sólo considerar la dimensión política que imprime a la sociedad en su conjunto, sino también, con ello, ampliar las posibilidades de prácticas, institucionalidades, discursos y performatividades que lo representan.

Hay que destacar el hecho de que ya no se pueden inscribir estas dinámicas únicamente en términos locales o nacionales. Precisamente la pluralización del espacio público y de las diversas prácticas institucionales que median las acciones sociales responde, cada vez más, a lógicas de articulación entre actores que van más allá de las fronteras (políticas, legales, culturales y sociales) de una nación. Como resalta Benjamín Arditi (2005:13), "los intercambios supranacionales disputan el encasillamiento de la política en el espacio físico del estado-nación, vale decir, cuestionan la reducción de lo externo a mera política exterior o relaciones internacionales". 
Las instancias multilaterales a nivel global donde hoy día se rigen muchos procesos políticos no sólo deconstruyen y abren los límites de los imaginarios nacionales, sino que los espacios de incidencia regional o global - como las Naciones Unidas (UN), la Organización de Estados Americanos (OEA), entre otros - se han transformado en actores fundamentales para la interacción entre agentes sociales para-estatales, ONGs, movimientos sociales, etc., incluso como un mecanismo de resistencia frente a los Estados-nación en lo que respecta a la atención de demandas de estos sectores. Como resalta Gina Romero (2018), las instancias multilaterales se transformaron en espacios de legitimación política de la sociedad civil. En sus palabras: "con el fortalecimiento de las sociedades civiles globales, los escenarios internacionales, se han vuelto por sí mismos un escenario de disputa, más allá de sus representación o soporte local, sobrepasando los debates sobre la legitimidad de los movimientos internacionales, que, en su mayoría, están representados por una élite ciudadana" (Romero 2018:112).

Es en este contexto donde debemos ubicar el rol de la sociedad civil como uno de los sectores fundamentales para delimitar las dinámicas socio-políticas contemporáneas en el espacio público. La sociedad civil se define, según Zapata Callejas y Sanín Eastman (2015:127), como "serie de individuos que convergen para un fin común y en pro del beneficio de una colectividad y se materializan concretamente en los movimientos sociales, nuevos movimientos sociales, organizaciones, asociaciones, grupos, colectivos, $\mathrm{ONG}$, sindicatos, minorías y demás, que se encuentran por fuera del Estado y que pueden buscar reivindicaciones, derechos, reconocimiento, emancipación y otros objetivos más"1. En este contexto, vale que destaquemos también que existe una tendencia en mostrar a la sociedad civil como un campo opuesto al Estado. Lejos de la idea de "más sociedad y menos política", en realidad estamos ateniendo a un concepto donde lo político trasciende las fronteras institucionales tradicionales y modernas, superando la visión del Estado como un lugar de gestión o administración hacia un locus de encuentro con la sociedad civil.

De aquí podemos entender la sociedad civil como un espacio atravesado por los antagonismos que representan una diversidad muy vasta de agenciamientos, los cuales forman parte de cualquier grupo social que, a su vez, tensiona los modos tradicionales de entender las prácticas políticas instituidas, refleja la diversidad de demandas presentes en la sociedad (muchas de ellas contrapuestas), presiona al Estado para encauzar acciones más focalizadas y participa de instancias regionales y globales, buscando apelaciones de articulación e incidencia más allá de la coyuntura nacional.

Al hablar de la relación entre voces religiosas desde esta comprensión del espacio público y de la sociedad civil, emerge un aspecto fundamental, a saber, el factor de cómo se comprende la pluralidad del campo religioso desde una dimensión política y sobre cómo los procesos de disputa ideológica hacia dentro del mismo seno de las religiones (sea internamente a las identificaciones específicas, como también en el marco de la relación entre distintas instituciones) impactan en lo público, como marco general de encuentro, diálogo y disputa de sentidos. 
Aquí es donde queremos destacar dos elementos analíticos que nos parecen pertinentes: la cuestión de la identidad religiosa y el impacto de una redefinición del espacio público sobre los estudios religiosos. Con respecto al primer elemento, las recientes teorías sobre la post-secularización cuestionan el trasfondo moderno y colonial del concepto de "religión" (Cavanaugh 2014), señalando la tendencia a definirlo como un campo de nociones homogéneas y fronteras extremadamente delimitadas (Ceriani 2013). Mark Chaves (1994) llega al punto de proponer que hay que dejar de lado la categoría de religión para hablar de secularización, ya que no estamos hablando del decline de lo religioso en sí, sino de la autoridad religiosa, es decir, de sus procesos de institucionalización, los cuales no dan cuenta de la foto completa.

El uso de identidad religiosa (o del abordaje del fenómeno religioso desde el concepto de identidad) ha permitido ampliar el estudio de los procesos de identificación religiosa, desde visiones estructuralistas (donde lo religioso en tanto campo simbólico es entendido como productor de acciones a priori a los sujetos), hacia comprensiones que problematizan los juegos de resistencia, negociación y redefinición entre las creencias, las instituciones, los discursos y el sentido de práctica de los sujetos. Además de eso, conceptos como el de "nuevos movimientos religiosos", religiosidad popular, creencias y espiritualidades, han presionado el desplazamiento del monopolio del concepto de religión hacia un conjunto de categorías que evidencian la multiplicidad de procesos en las vinculaciones entre estas esferas. Por último, una redefinición de lo religioso nos invita a pensar sobre su inherente dimensión socio-política. Es decir:

La religión, como los mitos, además de constituir un primer intento de dar razón de lo inexplicable, pone de manifiesto la capacidad y el anhelo del ser humano de trascender lo inmediato, mirando más allá de si mismo, o profundizando en su interior, en busca de un sentido que permita apaciguar, o aceptar, la zozobra de la existencia finita. (Camps 2014:13).

Con respecto al segundo eje - el impacto de una redefinición del espacio público sobre los estudios religiosos -, existen muchos elementos que podríamos mencionar, a saber, el tema de la laicidad, la relación Estado-iglesia, las mediaciones legales con respecto a lo religioso, los tipos de incidencia de las creencias sobre lo público, entre otros. Enfatizaremos concretamente tres elementos. Primero, a partir de lo que propone Verónica Giménez Beliveau (2008), necesitamos "romper con la perspectiva estado-céntrica" del debate sobre religión y política y abrirnos hacia comprensiones que inscriban esta vinculación, desde un marco que ubique a las creencias, los discursos teológicos y las instituciones religiosas en una noción de lo público como espacio de disputa de sentidos. Como propuso Charles Taylor (2010), es en el espacio de disputa de sentidos donde la fe y la creencia sean considerados como una opción más dentro de un complejo campo de interacción en torno a la definición por "lo 
común", lo que toca a un amplio conjunto de conceptos e instituciones, dentro de ellas el Estado, lo político, las prácticas democráticas, las políticas públicas, la atención a demandas concretas, entre muchos otros elementos.

Esto nos lleva a un segundo elemento, que es la comprensión de la relación entre Estado y religiones desde una política agonística, tal como presenta Chantal Mouffe (2005), como crítica al sentido de "neutralidad" del Estado que pregonan los modelos liberales. Luego de plantear que el liberalismo en sí mismo representa un marco ideológico no neutral, Mouffe (2005) sostiene que la distinción entre iglesia y Estado no implica necesariamente una neutralidad en materia religiosa. De aquí esta autora advierte que una cosa es hablar de la distinción entre Estado e iglesia, otra, de la separación entre religión y política y aún otra, de la diferencia entre lo privado y lo público.

En otras palabras, la necesaria separación entre iglesia (cristiana) y Estado no debe llevarnos a suprimir lo religioso como un asunto público, donde las religiones pueden ser reconocidas como agentes sociales en un mismo estatus de reconocimiento junto a otros sujetos, en torno a la deliberación por agendas comunes. Lo contrario sería promover un pluralismo ingenuo o políticamente correcto, sin considerar la validez de esta población en los procesos del espacio público.

Esto, en tercer y último lugar, nos trae también a otro dilema, que es la distinción entre lo privado y lo público. Sabemos que esta discriminación sirvió como una manera de separar esferas de dominio y de jerarquización de funciones sociales, no sólo con respecto a lo religioso sino a otros campos de la sociedad, como lo familiar o las distinciones de género. Podríamos afirmar que esta diferenciación tuvo un "efecto búmeran": mientras pretendió demarcar una delimitación entre las esferas de lo político y de lo no-político, en realidad terminó siendo, con el tiempo, la inscripción de dos campos que entrarían en disputa por el dominio de lo público. Richard Sennett (2011) ha demostrado cómo el ámbito de la familia, la sexualidad y todo lo referido a "lo privado" - distinguido de lo público, lo urbano, etc - fueron otorgados a la órbita de la tutela eclesial (especialmente desde una perspectiva simbólica), frente a los procesos de industrialización de los centros urbanos en el siglo XVIII. Pero lo privado como campo de dominio, lejos de ser un espacio no-político o no-público, terminó siendo, con el tiempo (y especialmente hoy), una bandera de incidencia por parte de muchos actores religiosos - principalmente cristianos -, donde la defensa del modelo tradicional de familia, de la sexualidad heteronormativa, entre otros elementos, se transformaron en pivotes de acción política y de incidencia en el espacio público.

En resumen, podemos concluir que, entendiendo lo público como un espacio hermenéutico de disputa de sentidos sociales, compuesto de un campo heterogéneo de actores de la sociedad civil que intervienen a través de diversas performances e institucionalizaciones de acción social, lo religioso ingresa como un agente fundamental, el cual ya no se mueve sólo dentro de la tensión que implica lidiar con una comprensión de laicidad o con la polarización que emana de la división iglesiaEstado. Sin embargo, lo religioso es como un sujeto socio-político que se constituye 
desde la misma diversidad que las OSC y que ingresa a la competencia pública, desde una pluralidad de propuestas e identificaciones que responden a las mismas demandas - inclusive antagónicas - de este sector. Es decir que dicha dinámica dista de ser homogénea, ya que "lo religioso" responderá a las propias tensiones ideológicas, políticas y valóricas de la sociedad civil. Ello conllevará construir distintos tipos de articulaciones con otros agentes políticos y prácticas de incidencia, que pueden ir desde la defensa de una agenda valórica heteronormativa en términos de género, hasta el acoplamiento a las distintas agendas de amplios sectores de la sociedad civil que militan desde heterogéneas apropiaciones sobre los derechos humanos, la pluralidad o las políticas inclusivas.

\section{Lo religioso como parte de la sociedad civil: la categoría de minoritización}

El concepto de minoritización es una categoría que nos puede ayudar a entender este proceso de mutación e inscripción de lo religioso en la sociedad civil y el espacio público, especialmente en términos de cómo expresiones "minoritarias" que ingresan al juego - desde las distintas perspectivas presentes en las OSC - tensionan las matrices de sentido y prácticas de incidencia hegemónicas (sea en la propia sociedad civil como en las instituciones religiosas). Uno de los principales analistas de este fenómeno es el politólogo especializado en asuntos religiosos Joanlido Burity. Este autor toma de los aportes del posestructuralismo - especialmente en Jacques Derrida, Ernesto Laclau y Chantal Mouffe - para dar cuenta de las dinámicas internas y externas - o lo que denomina como dimensión colectiva (la relación de lo religioso con movimientos sociales y políticos) y dimensión diseminativa (las modificaciones de lo religioso en las trayectorias políticas personales) - de las comunidades evangélicas en el Cono Sur, especialmente en Brasil y Argentina (Burity 2008b, 2009).

Burity (2008a, 2009) no sólo analiza los procesos particulares de redefinición de nociones políticas dentro de las comunidades religiosas - teniendo en cuenta la especificidad de los códigos teológicos a los cuales responden -, sino también pone en evidencia la transformación existente en la pluralización de instancias de trabajo conjunto entre religiones y Estado, como también la visibilización de lo religioso como una expresión más dentro del creciente espectro de organizaciones, movimientos sociales e institucionalizaciones alternativas de lo político.

Por ello, Burity $(2008 \mathrm{~b}, 2009)$ habla de tres aspectos centrales para comprender la relación entre política y pluralismo religioso, especialmente en América Latina. En primer lugar, las religiones son un elemento constitutivo de las sociedades del continente. En estas últimas décadas, dicha presencia se ha visto reflejada en una mayor interacción de gobiernos con iglesias y organizaciones religiosas en la ejecución de trabajos sociales, la atención al tema religioso por parte de organizaciones civiles, la inclusión de lo religioso como política cultural, entre otros. En segundo lugar, es posible analizar los fenómenos religiosos y su relación con el espacio público de la 
misma manera que la dinámica entre sociedad civil y Estado. Por último, los espacios religiosos son también campos de articulación de discursos e imaginarios políticos, con agendas públicas específicas.

Este autor utiliza el concepto de minoritización (Burity 2016, 2017) para hablar de las dinámicas políticas particulares de los grupos evangélicos. Él retoma ese concepto, principalmente, de Giles Deleuze, Felix Guattari y William Conolly, aunque también remita a autores como Jean-Luc Nancy, Jacques Derrida y Ernesto Laclau. Fundamentalmente, dicha categoría se refiere a dos factores centrales: primero, al proceso de pluralización de lo religioso, el cual no sólo pone en evidencia el fenómeno de la heterogenización del campo en sí, sino también de los procesos internos que viven las voces mayoritarias; y en segundo lugar - partiendo del aporte de organismos ecuménicos en el espacio público -, el lugar de organizaciones, iglesias y movimientos nutridos de una lógica religiosa, en instancias heterodoxas de incidencia social, en consonancia con la pluralización de las identidades políticas en las sociedades actuales.

Podríamos decir que el concepto de minoritización proviene, principalmente, de una visión más amplia de la concepción del espacio público. Burity (2005) lo describe desde una definición que trasciende la referencia estatista, ampliando su comprensión principalmente hacia el lugar de la sociedad civil y las nuevas dinámicas políticas que representa, especialmente la emergencia de otras formas de representatividad ciudadana. En concreto, Burity (2005) plantea una redefinición de lo público a partir de los cambios en las relaciones entre Estado, gobierno y sociedad civil, la transferencia de responsabilidades estatales a la sociedad y el esfuerzo de las OSC en la conformación de redes de incidencia.

Sin embargo, podríamos afirmar también que el concepto de minoritización no sólo remite a una dimensión descriptiva o a una lectura fenomenológica del proceso de diversificación del campo religioso, sino que ofrece, además, una forma de comprender las lógicas de minoritización constitutivas de la construcción de toda identidad, en este caso religioso. Con ello, pretendemos enfatizar el hecho de que una creencia particular posee la capacidad de construir dinámicas de resignificación hacia su interior, apelando a los mismos campos discursivos, pero remitiendo a prácticas y acciones diversas, inclusive de manera antagónica a las establecidas como hegemónicas.

Según Burity (2005), desde el concepto de minoritización, la categoría de identidad se transforma en una esfera de intersección entre sociedad civil y política, lo que nos lleva a ubicar a las identidades religiosas como instancias entre-medio de las lógicas políticas tradicionales. Más aún, dichas identidades se convierten en marcos de renegociación y tensión de las narrativas establecidas. En palabras de Burity (2008b:32): "Lo que las torna nuevas [a las identidades religiosas] no es un conjunto común de atributos, sino una circulación de temas y prácticas marcados por la experiencia de un dislocamiento de viejas formas de identificación (inclusive aquellas que muy recientemente se habían presentado como alternativas) y por la difícil y nunca garantizada aprendizaje de vivencia plural, de negociación entro el yo/nosotros o el 
otros/ellos". Aquí destacamos la importancia del concepto de ciudadanía como marco que permite reubicar la participación socio-política desde las disputas de sentido en un Estado de derecho, las políticas públicas y el propio tercer sector (Burity 2006).

Los espacios religiosos, según Burity (2006), aportan a la sociedad civil de tres maneras: como ambientes socializantes, fomentando el compromiso cívico de la membresía; como unidades social y cívicamente inscritas junto a otros espacios de incidencia; y como bases domésticas, dando soporte a miembros individuales en sus compromisos cívicos. Esta descripción conlleva a una complejización del entendimiento sobre la relación entre organizaciones religiosas y espacio público. Ello se refleja en una mayor relación entre organizaciones basadas en la fe $(\mathrm{OBF})$ y gobiernos, en la implementación de proyectos sociales; en las múltiples relaciones entre OBF y OSC, donde lo religioso se integra desde la lógica del respeto a la diversidad y se transforman en espacio de demanda identitaria dentro de un locus de pluralidad; y, por último, en el lugar que asumen organizaciones religiosas en espacios de incidencia de sociedad civil, tanto a nivel nacional como regional (Burity 2008a).

En este contexto, lo evangélico se inscribe como un "tercer espacio" que viene a disputar la hegemonía cristiana, especialmente de cuño católico. Esto cobra un lugar fundamental en el análisis político regional, teniendo en cuenta las vinculaciones orgánicas entre las cosmovisiones políticas latinoamericanas y la catolicidad. Pero en este contexto, lo pentecostal o neo-pentecostal se inscribe a su vez como un tercer espacio dentro del propio campo evangélico, planteando nuevas lógicas de diferenciación interna y externas. "Los pentecostales muestran una notable capacidad tanto para adaptarse como para ofrecer resistencia a expectativas de virtud republicana, pluralismo cultural y experimentación democrática de base. Por lo tanto, están claramente dentro y fuera de diferentes formas de construcción de lo común en sociedades que hacen frente a procesos de minoritización” (Burity 2016:104).

De esta manera, lo religioso se transforma en una expresión de la "política de la cultura" (Burity 2009), donde esta última se asume como un marco representacional de tensiones y articulaciones políticas e identitarias, así como en un espacio de visibilización de diferencias constitutivas y constituyentes. De aquí que lo religioso se define como un "significante flotante" (cf. Laclau 1996:69-86), que transita, tensiona y atraviesa dichas espacialidades. Burity (2016) aplica el concepto de hospitalidad derrideana, que ubica la discusión no sobre el hecho de si lo religioso tiene o no un lugar público, lo cual es evidente (Casanova 2012), sino en cómo "dejar entrar" a los actores religiosos a la escena pública (Burity 2015). Así, las comunidades religiosas se transforman en instancias de de-territorialización/re-territorialización, a nivel global y local. Esto es lo que Burity (2014) denomina como cosmopolitismo agonístico del campo religioso.

En conclusión, podemos resumir que el concepto de minoritización se vincula a cómo las comunidades religiosas - en este caso, evangélicas - inciden en el espacio público a través de la construcción de discursos y prácticas que tensionan las 
cosmovisiones e institucionalidades hegemónicas, sean políticas, sean religiosas. Es decir, se constituyen como zonas fronterizas y espacios entre-medio, desde la circulación de narrativas y prácticas dentro de la compleja sociedad civil. Esa es una manera de comprender la acción política, en términos foucaultianos, de abajo hacia arriba, donde las voces religiosas asumen un lugar de doble vía: de disputa de sentido y de articulación institucional. La incidencia religiosa deja de entenderse sólo como una pragmática institucionalista desde los lugares de poder instituidos, para comprenderse como un jugador fundamental de productor de suturas, conflictos y competencias dentro del fluido mundo de las OSC. En este sentido, las demandas levantadas por los grupos evangélicos, más allá de responder a especificidades identitarias (y, con ello, a un conjunto de matrices teológicas, históricas y genealógicas), asumen una instancia de atención frente a discursos, confrontaciones y carencias dentro de la sociedad civil, logrando, con ello, una dinámica de articulación con otros agentes sociales emergentes y de incidencia en distintos espacios (sean locales, sean globales), más allá de los lugares comunes, como el Estado o los partidos políticos, entre otros.

\section{Procesos de minoritización en el campo evangélico: algunas propuestas de análisis}

Si analizamos los procesos de incidencia pública del campo evangélico en América Latina, podemos identificar tres instancias principales: primero, la incidencia micro-social o comunitaria, que es la más enfocada en los procesos de influencia de iglesias evangélicas en espacios sociales concentrados, como pequeños grupos, comunidades, barrios o proyectos de asistencia, y también en el rol de individuos creyentes en la participación de espacios públicos; segundo, la incidencia a nivel nacional desde un encuadre institucional, que está focalizada en la conformación de partidos políticos a partir de la década de los 1980, en la complejización de procesos de lobby a través de partidos, municipios y Estados y en la participación en debates públicos sobre proyectos de ley; y, tercero, la incidencia transnacional, que está vinculada a la participación de sectores religiosos en organismos multilaterales, como la OEA, la Comisión Interamericana de Derechos Humanos (CIDH) y la UN, o a la conformación de "ministerios" con enfoque político y alcance regional.

El análisis de estas reconfiguraciones se ha vuelto uno de los campos de investigación más fecundos dentro de las ciencias sociales, orientado para el estudio del campo religioso en las últimas décadas (Bonino 1993; Cavalcanti 1993; Parker 1996; López 2004; Fediakova 2013; Panotto 2014). Los estudios de la relación entre evangélicos y espacio público varían según las orientaciones que se otorguen, tanto a la definición de la particularidad del sector como a su relación con lo socio-político. Es decir, los enfoques sobre grupos específicos que componen el campo, como los extensos trabajos sobre el pentecostalismo de Frigerio (1994), Semán (2000) y Anderson (2007); las definiciones sobre los tipos de campo de incidencia, como vemos en Carozzi (1993), Carbonelli (2011) y Mansilla, Orellana y Panotto (2019); 
o las maneras de definir el enmarque general, a partir del cual se entiende la relación evangélicos-política, como podemos leer en Panotto (2015a, 2015b).

Sin caer en reduccionismos analíticos, podríamos decir que el estudio de la incidencia evangélica en el espacio público del Cono Sur ha ido a la par de las transformaciones de la presencia política de dichos grupos en América Latina. Encontramos corrientes de estudio desde los siguientes campos: a) el impacto del crecimiento demográfico a partir de la década de los 1950; b) las primeras incursiones e intentos de conformación de partidos confesionales (Deiros 1986); c) el lugar de las comunidades evangélicas en las transformaciones dentro de los sectores populares a partir de la década de los 1990 en la coyuntura neoliberal de la región (Míguez 2000; Algranti 2006) d) y los nuevos procesos de articulación regional de movimientos evangélicos a partir de principios del 2000 (Carbonelli 2018).

Las investigaciones mencionadas se han concentrado más específicamente en el análisis de los dos primeros ejes indicados al inicio, a saber, las dimensiones micro-sociales y comunitarias del impacto que generan el trabajo de iglesias locales y experiencias individuales de creyentes, así como la incidencia dentro de una matriz nacional-estatal que implica la visibilización y movilización de algunos sectores de iglesias evangélicas. Sin embargo, hay muy pocos estudios concentrados en una mirada más bien regional y desde una dimensión política multilateral-internacional del campo (Anderson 2007; Contins 2008; Syan, Yong, Álvarez 2014).

Frente a este escenario, el concepto de minoritización desarrollado, en el marco de una noción complejizada del espacio público y de la diversificación de acciones del campo evangélico desde la sociedad civil, nos lleva a la necesidad de precisar cómo se despliega el proceso de auto-comprensión de los grupos evangélicos en términos de acción política y el impacto que ello tiene en diversos campos, especialmente en lo relacionado a la tensión que su intervención produce sobre "sentidos comunes" y prácticas establecidas en instancias locales, nacionales y regionales de incidencia. Para desarrollar esto a continuación, nos concentramos en dos temas, a modo de ejemplo: (1) la necesidad de diversificar y complejizar las categorizaciones sobre el campo evangélico, especialmente a partir del uso de "la agenda valórica" por parte de alguno de los grupos que lo componen, y (2) las transformaciones que existen en la actualidad en términos de la incidencia evangélica en el sistema interamericano. Ambos temas nos servirán para comprender cómo la lógica de minoritización del campo evangélico ha ido mutando, tanto en términos de conceptualización como de alcance, en este caso a nivel regional.

Sobre la necesidad de diversificar los modos de categorizar el propio campo evangélico, ya sabemos que éste representa la primera minoría religiosa en América Latina, luego de la iglesia católico-romana. Su proceso de crecimiento desde la década de los 1950, especialmente bajo la figura del pentecostalismo, ha hecho que este conjunto de iglesias y organizaciones alcancen un logar fundamental en los procesos dentro del espacio público latinoamericano, al punto, en algunos casos, de transformarse en un agente determinante frente a ciertas coyunturas políticas. 
Ante todo, vale aclarar que el campo evangélico es sumamente heterogéneo.Con respecto a los modos de vinculación entre evangélicos y política, podemos analizarlo desde una perspectiva denominacional (es decir, de cómo cada actor entiende dicho vínculo) como también desde "tipos ideales" sobre la relación, que entrecruzan de manera más compleja las relaciones, y más allá de las especificidades identitarias. Con respecto a esta última, se pueden destacar tres modos: uno más bien crítico-progresista, ligado a espacios ecuménicos, con la influencia en la teología de la liberación, en el compromiso con modelos políticos de izquierda y en un discurso afín con los derechos humanos; otro neo-conservador, rozando en algunos casos el fundamentalismo, donde la relación se gesta en términos morales, a través de la defensa de una agenda valórica tradicional y con diversos niveles de incidencia política (desde comunidades con trabajos más localizados hasta otras con gran presencia en la burocracia política institucional y hasta lobby político); y una tercera categoría que podemos llamar como congregacionalismo progresista, el cual representa un conjunto de iglesias y grupos que no quieren relacionarse con el espectro conservador y fundamentalista, pero tampoco con el "extremo" - según afirman - de los espacios ecuménicos. Este último representa un espectro muy difuso y heterogéneo de expresiones evangélicas tradicionales que cuestionan muchas prácticas conservadoras, especialmente en términos de incidencia social, pero se mantienen al margen de temáticas sensibles, especialmente relacionadas con cuestiones de género.

Así y todo, estas tres tendencias tampoco representan todos los posibles modos de identificación entre campo evangélico y política. En cada uno de estos conjuntos podemos encontrar tipos muy disímiles y hasta antagónicos. Como sabemos, el reconocimiento de un marco discursivo o identitario no implica necesariamente que las comunidades locales o los sujetos creyentes particulares asuman y resignifiquen dichos lineamientos de manera exclusiva.

Desde una visión sobre los procesos de minoritización, podríamos formular las siguientes preguntas: icómo identifican las iglesias evangélicas su rol político y su lugar en el espacio público? ¿Cómo actúa la distinción entre religión y política, lo sagrado y lo profano, la iglesia y el mundo, como dispositivos cosmovisionales de incidencia? ¿De qué manera lo evangélico tensiona y resignifica prácticas y nociones socio-políticas? ¿Qué rol ha jugado la iglesia evangélica en la reconceptualización de un Estado laico?

Para responder a estas preguntas, nos concentraremos en el análisis de algunos hechos concretos dentro del sector neo-conservador, el cual está cobrando cada vez mayor visibilidad a nivel público, desde una escala nacional hasta regional. El primer elemento a resaltar es la manera en que estas iglesias evangélicas han ido mutando en la concepción de su rol político. Durante los años 1980, con el regreso de los procesos democráticos en América Latina, existieron intentos de conformar partidos políticos evangélicos, instancias que finalmente fracasaron. La disolución de estos esfuerzos hizo que sus integrantes se distribuyeran en partidos políticos tradicionales en sus países y continuaran su tarea de incidencia desde 
ellos (Wynarczyk 2009, 2010). Valga destacar que estos esfuerzos eran coordinados por individuos pertenecientes a iglesias y no por estructuras eclesiales de manera oficial e institucional. Por entonces, persistía en las iglesias una gran resistencia a comprometerse con el campo político.

Durante la década de los 1990, a pesar de la ausencia de una presencia notoria de creyentes (al menos asumidos explícitamente) dentro de esfuerzos partidarios o en posiciones legislativas, las iglesias evangélicas en tanto comunidades locales lograron un notorio crecimiento y una influencia importante en sectores postergados de las sociedades latinoamericanas. Tal como plantea Daniel Míguez (1999), en el caso del pentecostalismo argentino, dicha presencia se da en un contexto de ausencia estatal y de políticas públicas sobre necesidades fundamentales.

En esta década, se evidencia un giro en varios sentidos. Por un lado, la "geografía" de los grupos evangélicos cambia (especialmente en los grupos neopentecostales), a través de un desplazamiento desde sectores populares a otros más cercanos a la clase media y media-alta. Esto se contrapone a algunos análisis tradicionales que ven la presencia evangélica (especialmente pentecostal) sólo en sectores pobres. Por otro lado, es un período de grandes crisis sociales en diversos países del continente, especialmente entre 1995 y 2002. Esta coyuntura hizo que muchas comunidades evangélicas replanteen su protagonismo político, por lo cual se comenzó a evidenciar no sólo la presencia de actores individuales sino también de iglesias y denominaciones en instancias como asambleas barriales, trabajos articulados con ONGs, diálogo con municipios, ministerios provinciales y nacionales, para el desarrollo de acciones de contingencia, entre otros esfuerzos. Esto es lo que Hilario Wynarczyk (2009) denomina como el paso de un dualismo negativo (donde existía una distinción marcada entre iglesia y mundo, sin muchas vías de conexión entre uno y otro) a un dualismo positivo (donde la distinción iglesia-mundo se sostiene, pero ahora desde una vocación de moralización social, es decir, donde la iglesia se siente apelada a responder a la crisis del contexto para cambiarlo).

Aquí surge el segundo elemento a considerar: esta transformación en torno a la auto-percepción de la dimensión política de las iglesias (donde lo político ya no significaba solamente un modo de hacer presencia en cuerpos partidarios o estructuras institucionales establecidas sino con la vivencia de la fe, del quehacer eclesial y la propia dinámica del "mundo espiritual" en la cotidianeidad de los creyentes y comunidades), deriva en la construcción de un tipo de incidencia centrada en la promoción de una agenda valórica, focalizada en temas de sexualidad, género y familia, y desde allí en la oposición a temas tales como políticas públicas de educación sexual, matrimonio igualitario, despenalización y legalización del aborto, entre otros. En otros términos, el tipo de incidencia se focaliza en la construcción de una cultura de enclave, o como propone Marcos Carbonelli (2011), una política de la moralización. Esto no quiere decir que la percepción política de estas comunidades haya dejado de lado otros campos, a saber, una idea de incidencia en términos de desarrollo social, 
educación, salud o crecimiento económico. Pero estas mismas acciones son vistas como respuestas a la promoción de una escala moral, donde los significantes "familia" y "valores" asumen un lugar central y distintivo con respecto a otros proyectos.

Los ejemplos que podríamos mencionar en esta línea son muchos: la campaña "Con mis hijos no te metas" en Perú, las movilizaciones en contra de la legalización y despenalización del aborto en Chile y Argentina, la acción conjunta entre evangélicos y católicos para frenar la ley integral de educación sexual en Panamá, el impacto de la bancada evangélica en Brasil con respecto al tratamiento de agendas en derechos humanos, o la victoria del "no" en la primera consulta popular en Colombia por el proceso de paz, resultado en gran medida atribuido a la movilización de iglesias evangélicas que relacionaban el tratado con la ideología de género, entre otros tantos más.

Ya hemos planteado que este proceso emerge como consecuencia de la distinción de esferas entre lo público y lo privado en la modernidad, donde lo considerado "nopolítico" se levanta para tensionar las fronteras de la política. Pero además de esto, existen dos factores a destacar. Primero, que no es casualidad que estas agendas alcancen mayor visibilización en un momento de coyuntura política regional de grandes polarizaciones, a partir de la llegada de gobiernos de un nuevo cuño ideológico entre el 2000 y 2015 (denominados populistas, progresistas, de izquierda), los cuales asumieron un marco más centrado en un discurso alineado con los derechos humanos. De aquí el protagonismo de algunas iglesias evangélicas con su agenda políticomoral responde no sólo a un posicionamiento histórico, sino a la atención de una coyuntura particular. En ello, oponerse a diversos proyectos de ley o promover ciertos temas implica tomar una posición en términos políticos y servir como catalizador de un escenario de disputa de sentidos, articulándose, de esa manera, a parte de la ciudadanía como también a espacios políticos, OSC y hasta partidos, dentro de un marco mucho más amplio de moralización y transformación (cuasi mesiánica) de un escenario "corrupto" en términos políticos como sociales y morales.

En otros términos, las banderas políticas de algunos grupos evangélicos no responden solamente a la visibilización de un posicionamiento identitario particular, sino a una acción intencional de articulación con un conjunto de fenómenos políticos más amplios, donde se ubica a las iglesias como un agente de mayor confiabilidad y empatía que otros actores sociales, incluyendo los emergentes. Es decir, las iglesias están adquiriendo gran capital simbólico en una coyuntura de resignificación de lo político, desde un discurso que se presenta como "des-ideologizado" y en un clima de descreimiento y desencantamiento con la política tradicional. Más aún, aquí vemos cómo la lógica de minoritización de cierto sector evangélico, a pesar de sus límites en términos de densidad demográfica, actúa como catalizador de un escenario de crisis social más amplio, donde dichas voces se asumen como instancias de disputa de sentido frente a otros agentes políticos y de la sociedad civil, que comenzaron a ser cuestionados, sea por el arrastre de la propia crisis de los gobiernos progresistas de turno, como también a causa de las tensiones que se produjeron hacia dentro de la misma sociedad 
por el tratamiento de políticas sociales y públicas en torno a temas sensibles, como los vinculados a la comunidad LGBTIQ, feminismo, educación sexual, entre otros.

Aquí un segundo elemento: la dimensión política de muchos grupos evangélicos se trasluce en instancias de articulación y diferenciación (intra y extra-eclesial). Por un lado, llama la atención que lo que la teología no pudo hacer por siglos, lo logre la movilización social - nos referimos al nuevo "ecumenismo" entre iglesias evangélicas y católicas. Por otro lado, es cada vez más notoria la incidencia de sectores evangélicos a nivel de sistema interamericano, como veremos más adelante. En todos estos casos, la acción política se realiza con un gran nivel de organización, institucionalidad y formalidad, y con agendas muy concretas en torno a la articulación no sólo entre sí, sino con otros actores políticos que persiguen los mismos objetivos.

Ahora bien, aquí vale advertir lo siguiente: los resultados de este tipo de incidencia no son homogéneos. Veamos el ejemplo de Colombia: mientras la movilización de iglesias evangélicas por el "no" al proceso de paz logró un gran impacto, los pastores y candidatos evangélicos referentes de esta campaña que se postularon en las elecciones parlamentarias unos meses después, no lograron apoyo de estas mismas iglesias. Lo mismo podríamos identificar en las últimas elecciones primarias, también llamadas Primarias, Abiertas, Simultáneas y Obligatorias (PASO) en Argentina: la fórmula que se presentó como "la opción evangélica", compuesta por Juan José Gómez Centurión y Cynthia Hotton, la cual obtuvo apoyo mediático de famosos pastores y de ACIERA, la federación evangélica más grande del país, por su militancia a favor de la vida y la familia, y por ende en contra de cualquier política a favor de la legalización y despenalización del aborto, finalmente logró alcanzar sólo unos 2,84\% de los votos. Dicha cifra es sumamente baja, si la comparamos con los 9\% de evangélicos que componen al país.

Esto nos permite identificar una operación fundamental: a la hora de defenderse frente a lo que se entiende como una amenaza a algún elemento constitutivo de la iglesia, como lo representa lo que se denomina como "ideología de género", las comunidades neoconservadoras actúan casi en bloque. Pero esta realidad no necesariamente se traducirá en resultados electorales, donde las opciones partidarias son mucho más diversas. Aquí sobresale la complejidad que existe en la relación entre institucionalidad política y eclesial: las visiones del liderazgo y la comunidad general no siempre coinciden. Por ello, la relación entre lo evangélico y la política manifiesta escenarios muy complejos y heterogéneos. Como concluye Marcos Carbonelli (2018), analizando el caso de la iglesia cristiana en Argentina y el debate sobre la legalización del aborto:

La influencia que las instituciones religiosas tienen sobre la clase política no se condice con su debilitada presencia en el plano de las decisiones vitales de la ciudadanía. En otras palabras: las jerarquías religiosas tienen más llegada a las alturas del poder que en el llano de 
las dinámicas cotidianas, donde creyentes y no creyentes resuelven sus opciones íntimas de manera autónoma. (Carbonelli 2018:[s.p.]).

Los procesos de articulación de estas lógicas de minoritización no sólo muestran un nivel de organización en la incidencia de estos grupos, sino también la apropiación de un modus operandi que tiene por objetivo aprovechar la brecha que se abre a partir de la crisis de credibilidad de los discursos y prácticas políticas monopólicas, a partir de un conjunto de acciones centradas en la lógica de OSC, como un espacio creciente de disputa a nivel nacional, regional y global.

De aquí destacamos cómo, en este período, se hace evidente un cambio de estrategia política, especialmente de los sectores evangélicos neo-conservadores, en lo que se refiere al alcance regional y su inscripción dentro de instancias de incidencia multi-lateral, como es el sistema interamericano. Son muchos los esfuerzos que podríamos mencionar. En este caso, nos centraremos más concretamente en el protagonismo que alcanzaron algunos agentes evangélicos en instancias políticas a nivel regional como también multilateral. Por ejemplo, tenemos el caso de Parlamento y fe, un ministerio internacional que comenzó a operar en 2009 en América Latina, empezando en Argentina, pero actualmente con presencia en Paraguay, Bolivia, México, Uruguay, Venezuela, Colombia, hasta España e Italia. En sus inicios, comenzó siendo un ministerio que organizaba encuentros de oración y reflexión bíblica en municipios para legisladores y políticos, y que atendía pastoralmente a dirigentes que lo solicitaban. Con el tiempo, han logrado tener encuentros con muchos partidos y funcionarios políticos, participar de instancias de consulta (local y regional), como también organizar encuentros entre legisladores evangélicos de todo el continente para establecer estrategias comunes.

Otro de los esfuerzos reconocidos es el Congreso Iberoamericano por la Vida y la Familia, un evento de alcance latinoamericano cuya primera convocatoria fue en 2017 y que a partir del segundo encuentro, en febrero de 2018, estableció una agenda de trabajo a nivel político, con cinco puntos muy concretos, a saber: (1) desarrollar mecanismos de coordinación con otras entidades iberoamericanas que comparten objetivos; (2) poner en marcha un Centro de Estudios; (3) preparar coaliciones de ONGs para lograr presencia y voz en asambleas de la OEA y en otras organizaciones internacionales; (4) lanzar un medio evangélico para Latinoamérica en formato digital, y (5) conformar una Fraternidad de Parlamentarios Evangélicos.

La incidencia de este grupo se concretizó en la asamblea de la sociedad civil de la OEA en Washington, entre el 4 y 5 de junio de 2018. Lograron inscribir tres coaliciones, en representación de 37 organizaciones civiles: la Coalición Congreso Evangélico Iberoamericano, la Coalición Brasileira y la Coalición Educación y Cultura por la Democracia. Las demandas fueron en la misma línea: el reclamo de la postergación histórica de los sectores evangélicos dentro de la OEA, la defensa "científica" de la gestación de la vida desde la concepción, y el rechazo a las políticas que vayan 
en contra de la familia tradicional como núcleo central de la sociedad. Todos estos puntos son enunciados desde un discurso que apela a la sensibilidad por los derechos humanos y la defensa de la vida.

Para ver la heterogeneidad de la presencia religiosa en la sociedad civil dentro de estos organismos, en esa misma asamblea, también participó la Coalición Religiones, creencias y espiritualidades en diálogo con la sociedad civil. Dicha coalición, tal como lo menciona en su discurso en la asamblea, representa:

[...] un conjunto de más de veinte organizaciones de todo el continente latinoamericano y caribeño, que pertenecen a Organismos Basados en la Fe como a la sociedad civil, y que trabajan articuladamente en la visibilización de las cosmovisiones críticas desde las múltiples formas de vivir la fe y las creencias, con base en los derechos y dignidad humana, además del desarrollo y promoción de políticas inclusivas, tal como lo legitiman los instrumentos internacionales de derecho. (GEMRIP 2018:1).

Esta coalición es el resultado del trabajo conjunto entre dichos actores religiosos con la Red Latinoamericana por la Democracia (REDLAD), una organización que nuclea a más de trescientos organismos de sociedad civil en todo el continente.

En resumen, podemos decir que una lectura del campo evangélico desde la lógica de la minoritización nos lleva a identificar las tensiones y divergencias que se gestan en el propio seno de dicho campo, como lo representa una temática tan presente y sensible como es la defensa de la agenda valórica, lo que nos indica que los procesos de identificación política evangélica distan de ser homogéneos. A su vez, esta lógica - la cual, como vimos, puede tomar un conjunto muy variado de representaciones y performances -, se inscribe dentro de un campo de disputa política mucho más amplia, haciendo que sectores evangélicos actúen como catalizadores de conflictos de sentido social y respondan a demandas específicas en contextos de crisis y pérdida de legitimidad de agentes o discursos políticos, dando lugar a una diversificación de articulaciones y juegos institucionales.

\section{Conclusiones}

Podemos concluir que existe una mutación en el modo en que los grupos evangélicos perciben su rol socio-político, pasando de ser un fenómeno exógeno a un elemento constitutivo de su ser-iglesia. De esta manera, podemos relacionar la resignificación de la dimensión política de las comunidades evangélicas con las transformaciones del mismo campo político a nivel regional, donde se evidencia un mayor predominio del rol social de nuevos sujetos y OSC, los cuales no sólo se vinculan, sino que tensionan, subvierten y desafían las nociones tradicionales de la 
política y sus instituciones. En este caso, lo religioso no denota solamente un marco identitario, sino también un epicentro desde donde discernir lo político.

Esto nos lleva a confirmar que la incidencia centrada en una agenda valórica implica no sólo la defensa de un posicionamiento particular de algunas iglesias dentro de esta expresión religiosa, sino la demarcación de una frontera de disputa con otros actores socio-políticos. "Lo privado", campo históricamente tutelado por lo eclesial, asume su impacto político al enmarcarse como una manera de confrontar otros sentidos y prácticas dentro de un espacio público heterogéneo y plagado de polarizaciones, asumiendo una manera de encauzar otros procesos, como respuesta a la demanda por estabilidad social, renovación política o la construcción de nuevas prácticas de incidencia, por parte de sectores sociales y de grupos políticos, sean de la sociedad civil como parte de la institucionalidad gobernante.

En otros términos, las "agendas valóricas" que representan las militancias de sectores evangélicos neo-conservadores se han transformado en un locus de disputa de sentido social desde una amplia comprensión, que involucra un conjunto variado y heterogéneo de agentes sociales y que, a su vez, responde a un campo muy diverso de demandas sociales, más aún en una coyuntura de polarizaciones y desgaste social con respecto a los modelos de política tradicional.

El asunto de "lo religioso" se ha transformado también en una trama de disputa y tensión hacia el interior de las OSC. Históricamente, estas últimas se han resistido a articularse con organismos religiosos, como resultado del fuerte laicismo que reinó entre ellas y que las llevó a negarse a la integración con agentes eclesiales, los cuales también se han mantenido al margen de su campo de acción. En vistas de las transformaciones enunciadas, diversos grupos que componen el conglomerado de las OSC han creado instancias de diálogo con el campo religioso, creando puentes, acciones conjuntas y diálogos, como también articulándose para el desarrollo de diversos proyectos.

Estas coyunturas, en sus diversas expresiones y posicionamientos ideológicos, no sólo es resultado de la creciente presencia de lo religioso en el espacio público, sino también de que las organizaciones e instituciones religiosas otorgan un marco de legitimación simbólica y social en un contexto de antagonismos, tensiones y polarizaciones. En otros términos, la emergencia de sectores religiosos en la sociedad civil también responde a fenómenos socio-políticos que exceden la sola intencionalidad de participación o protagonismo religioso.

Por último, vemos cómo estas dinámicas dan cuenta del escenario emergente sobre los procesos políticos (locales y globales), como también una nueva manera de concebir la relación entre religiones, política y espacio público. Aquí, los juegos hermenéuticos, las demandas como epicentros de construcción política, las tensiones por las dinámicas interpretativas, los procesos de lobby e incidencia, entre otros, dan cuenta de un escenario de profundo cambio en la comprensión de un fenómeno político que está traspasando ciertos reduccionismos locales y se está transponiendo en un campo de incidencia global. 
Los ejemplos dados hasta aquí no sólo dan cuenta de un modo de acción en un contexto post-secular, sino también advierten sobre posibles límites y reduccionismos que, por más que den lugar a la acción de un conjunto de actores (en este caso religiosos), llevados a cierto punto, pueden ocasionar la obturación de un ambiente democrático plural. Muchos de estos escenarios que se están promoviendo desde el campo evangélico neo-conservador presentan esta paradoja de, por un lado, utilizar los mecanismos de incidencia multilateral conquistados gracias a amplios debates democráticos regionales, pero, por otro, fomentando discursos y agendas que pueden clausurar dichos espacios para ciertas agendas y actores adversarios.

Lo descrito hasta aquí nos deja ver que los actores religiosos, en este caso evangélicos neo-conservadores, están ganando un lugar cada vez más notorio en el espacio público y, desde allí, construyendo nuevos puentes con la sociedad civil. Esto nos muestra, por un lado, que "lo religioso" ingresa como un significante que pluraliza

y tensiona las cosmovisiones y prácticas hegemónicas, pero también, por otro lado, produce instancias tanto de articulación como de disputa por sentidos que van mucho más allá de lo propiamente religioso. Es decir, las comunidades evangélicas no pretenden solamente ser un agente protagónico en una estructura institucional específica, sino provocar mutaciones mucho más extensas. Es aquí donde la intención de formar parte de escenarios multilaterales, cobra una importancia vital para alcanzar una visibilidad e incidencia más notorias.

\section{Referencias bibliográficas}

AAVV. (2010), Democracia, ien qué estado?. Buenos Aires: Prometeo Libros.

ALGRANTI, Joaquín. (2006), "Notas para el estudio de las comunidades pentecostales". Scripta Ethnologica, XXVIII: 95-120

ARDITI, Benjamín. (2005), "Introducción". In: Benjamín Arditi (ed.). iDemocracia post-liberal? El espacio politico de las asociaciones. Barcelona: Anthropos.

ANDERSON, Allan. (2007), El pentecostalismo. Madrid: Akal

BÉLIVEAU, Verónica Gimenez. (2008), "Espacios públicos y espacios políticos redefinidos. Reflexiones sobre el accionar de los grupos religiosos en la escena pública en Argentina". In: Catalina Romero (coord.). Religión y Espacio público. Lima: CISEPA.

BONINO, Míguez. (1993), Rostros del protestantismo latinoamericano. Buenos Aires: Nueva Creación.

BURITY, Joanildo. (2005), "Religião e república: desafíos do pluralismo democrática". Cuadernos de Estudos Sociais, v. 21, n. 1-2: 23-42

. (2006), "Cultura e identidad nas políticas de inclusao social". In: Aécio Amaral Jr., Joanildo

Burity (orgs.). Inclusao social, identidades e diferenca. Annablume: San Pablo.

. (2008a), "Religião, política e cultura". Tempo Social, v. 20, n. 2: 83-113.

. (2008b), "Cultura, identidades e inclusão social: o lugar da religião para seus atores e interlo-

cutores". Debates do Ner, v. 2, n. 14: 23-43.

. (2009), "Religião e lutas identitárias por cidadania e justiça: Brasil e Argentina". Ciências Sociais Unisinos, v. 45, n. 3: 183-195.

(2014) "Latin American Pentecostalism and ecumenical alterglobalism as cases of agonistic 
cosmopolitanism”. In Mario Rovisco y Sebastián Kim. (eds.) Cosmopolitanism, Religion and the Public Sphere. London/New York: Routledge

. (2015), "A cena da religião. Contingência, dispersão e dinâmica relacional". Novos Estudos. CEBRAP, n. 102: 89-105

. (2016), "Minoritization and Pluralization. What Is the 'People' That Pentecostal Politicization

Is Building?". Latin American Perspectives. i. 208, v. 43, n. 3: 116-132.

. (2017), "Autoridad y lo común en procesos de minoritización. El pentecostalismo brasileño". Revista latinoamericana de investigación crítica, a. IV, n.6: 99-125.

BUTLER, Judith; SPIVAK, Gayatri Chakravorty. (2009), ¿Quién le canta al estado-nación? Lenguaje, política, pertenencia. Buenos Aires: Paidós.

CAMPS, Victoria. (2014), "La secularización inacabada". In: Daniel Gamper (ed.). La fe en la ciudad secular. Laicidad y democracia. Madrid: Ediciones Trotta.

CARBONELLI, Marcos. (2011), "Ciencias Sociales, evangélicos y política. Una lectura sobre la producción científica acerca de la participación política evangélica en la vida democrática argentina (1983-2010)". Revista Cultura y Religión, v. V, n. 2: 96-116.

CAROZZI, María Julia. (1993), "Tendencias en el estudio de los nuevos movimientos religiosos en América: Los últimos 20 años”. Sociedad y Religión, n. 10/11: 3-23.

CASANOVA, José. (2012), Genealogías de la secularización. Barcelona: Anthropos.

CALVACANTI, Robinson. (1993), "Evangelio y política en América Latina”. In: AAVV. CLADE III. Buenos Aires: FTL.

CAVANAUGH, William T. (2014), "The Invention of the Religious-Secular Distinction”. In: William Barbieri Jr. (ed.). At the Limits of the Secular. Grand Rapids: Eerdmans.

CERIANI, Cesar. (2013), "La religión como categoría social: encrucijadas semánticas y pragmáticas". Cultura y Religión, v. VII, n. 1: 10-29

CHAVES, Mark. (1994), "Secularization as Declining Religious Authority". Social Forces, v. 72, n. 3: 749-774.

CONTINS, M. S. (2008), "Religião, Etnicidade e Globalização: uma comparação entre grupos religiosos nos contextos brasileiro e norte-americano", Revista de Antropologia, n. 51: 67-106.

DEIROS, Pablo. (1986), Los evangélicos y el poder político en América Latina. Buenos Aires: Nueva Creación.

FEDIAKOVA, Evguenia. (2013), Evangélicos, política y sociedad en Chile: dejando "el refugio de las masas". 1990-2010. Santiago: CEEP-IDEA-UdeSantiago.

FRIGERIO, Alejandro. (1994), "Estudios recientes sobre el Pentecostalismo en el Cono Sur: problemas y perspectivas". In: Alejandro Frigerio (ed.). El Pentecostalismo en Argentina. Buenos Aires: Centro Editor de América Latina Biblioteca Política Argentina.

HABERMAS, Jurguen. (2009), Historia y crítica de la opinión pública. Buenos Aires: Editorial Gili.

LACLAU, Ernesto. (1996), Emancipación y diferencia. Buenos Aires: Ariel.

. (2000), Nuevas reflexiones sobre la revolución en nuestro tiempo. Buenos Aires: Nueva Visión.

LACLAU, Ernesto; MOUFFE, Chantal. (2006), Hegemonía y estrategia socialista. Buenos Aires: FCE.

LEFORT, Claude. (1990), La invención democrática. Buenos Aires: Nueva Visión.

LÓPEZ, Darío. (2004), La seducción del poder. Los evangélicos y la política en el Perú de los noventa. Lima: Puma.

MARTÍN, Eloisa. (2007), "Aportes al concepto de 'religiosidad popular': una revisión de la bibliografía argentina”. In: Julia Carozzi; Cesar Ceriani. Ciencias sociales y religión en América Latina. Buenos Aires: Editorial Biblos.

MANSILLA, Miguel, ORELLANA, Luis; PANOTTO, Nicolás. (2019), "La participación política de los evangélicos en Chile (1999-2017)”. Revista Rupturas, v. 9, n. 1: 179-208.

MÍGUEZ, Daniel. (1999), "Why Are Pentecostals Politically Ambiguous? Pentecostalism and Politics in Argentina 1983-1995”. European Review of LatinAmerican and Caribbean Studies, n. 67: 57-74. . (2000), "Modernidad, posmodernidad y la transformación de la religiosidad de los sectores 
medios y bajos en América Latina”. Revista Ciencias Sociales, n. 10: 56-68.

MOUFFE, Chantal. (2005), "Religion, Liberal Democracy, and Citizenship". In: Hent de Vries; Lawrence Sullivan (eds.). Political Theologies. Public Religions in Post-Secular World. Nueva York: Fordham University Press.

. (2007), En torno a lo político. Buenos Aires: FCE.

PANOTTO, Nicolás. (2014), "Pentecostalismos y construcción de identidades sociopolíticas". Desafíos, v. 26, n. 2: 73-96.

. (2015a), "Pluralismo político y pluralismo religioso: nuevos escenarios y matrices analíticas de la relación”. In: Juan Mauricio Renold (ed.). Religión: estudios antropológicos sobre sus problemáticas. Buenos Aires: Editorial Biblos.

. (2015b), "Religión, ciudadanía y espacio público: un acercamiento socio-antropológico y teo-

lógico". Perspectivas Internacionales, v. 11, n. 1: 63-113.

PARKER, Christian. (1996), Popular Religion and Modernization in Latin America. New York: Orbis Books; Maryknoll.

RANCIÈRE, Jacques. (1996), El desacuerdo. Buenos Aires: Nueva Visión.

. (2007), El odio a la democracia. Buenos Aires: Amorrortu.

. (2010), Momentos políticos. Buenos Aires: Capital Intelectual.

ROMERO, Gina. (2018), "Tendencias de la Internacionalización de la Participación Ciudadana en América Latina”. In: Luz Elena Baños Rivas (comp.). Ciudadanía y sociedad civil latinoamericana: entre el desconcierto y el aprendizaje. México: Secretaría de Relaciones Exteriores.

SEMÁN, Pablo. (2000), "El pentecostalismo y la religiosidad de los sectores populares". In: Maristela Svampa (ed.). Desde abajo: la transformación de las identidades sociales. Buenos Aires: Biblos.

SENNETT, Richard. (2011), El declive del hombre público. Barcelona: Anagrama.

SYAN, Winson; YONG, Amos; ÁlVAREZ, Miguel (eds.). (2014), Global Renewal Christianity. Past, present and future. Florida: Charisma House.

TAYLOR, Charles. (2010), Uma Era Secular. San Leopoldo: Editora Unisinos.

VELÁZQUEZ, Fabio; GONZÁLEZ, Esperanza. (2009), "Institucionalidad participativa en Colombia: balance y retos". In: Lizandra Seraïm; José Antonio Moroni (orgs.). Sociedad civil y nuevas institucionalidades democráticas en América Latina: dilemas y perspectivas. San Pablo: Instituto Pólis/Instituto de Estudos Socioeconômicos.

WYNARCZYK, Hilario (2009). Ciudadanos de dos mundos. El movimiento evangélico en la vida pública argentina 1980-2001. Buenos Aires: UNSAM Edita

. (2010). Sal y luz a las naciones. Evangélicos y política en la Argentina (1980-2001). Buenos Aires: Instituto Di Tella-Siglo XXI

ZAPATA CALLEJAS, John Sebastian; SANÍN EASTMAN, José Alejandro. (2015), "Sociedad civil global: ¿a qué se está asistiendo?". Trans-pasando Fronteras: revista estudiantil de asuntos multidisciplinares, n. 7: 125-148.

\section{Otras referencias}

CARBONELLI, Marcos. (2018), "Poder religioso sociedad y clase política: a propósito del debate sobre la despenalización del aborto”. Revista Oleada, 30 jul. 2018. Disponible en: < https://oleada.com.ar/ cuarta-ola/poder-religioso-sociedad-y-clase-politica-a-proposito-del-debate-sobre-la-despenalizacion-del-aborto/>. Consultado en: 6 feb. 2019.

GEMRIP - Grupo de Estudios Multidisciplinarios sobre Religión e Incidencia Pública. (2018), Coalición Religiones, Creencias y Espiritualidades en Diálogo con Sociedad Civil. Documento Interno. 


\section{Notas}

1 Las acciones de la sociedad civil se encaminan en "conductas que resultan de la acción intencionada de individuos y grupos en el escenario público, en pros de metas específicas, en función de intereses diversos y en el contexto de tramas concretas de relaciones sociales y de poder [...para que] los individuos o grupos, en función de sus respectivos intereses (de clase, de género, de generación, étnicas) intervengan en el escenario público, directamente o por medio de sus representantes, para obtener bienes y servicios específicos (materiales y simbólicos) y/o incidir en decisiones colectivas relacionadas con la distribución de éstos. Pueden desarrollarse a través de canales institucionales o de manera informal” (Velázquez, González 2009:45).

Submetido em: 09.02.2019

Aceito em: 17.03.2020

Nicolás Panotto* (nicolaspanotto@gmail.com)

* Licenciatura en Teologia por el IU ISEDET, Argentina; Mestre en Antropología Social por la Facultad Latinoamericana de Ciencias Sociales (FLACSO), Buenos Aires, Argentina; Doctor en Ciencias Sociales por FLACSO, Buenos Aires, Argentina; Investigador Asociado del Instituto de Estudios Internacionales (INTE) de la Universidad Arturo Prat; Director general del Grupo de Estudios Multidisciplinarios sobre Religión e Incidencia Pública (GEMRIP); Membro de la dirección de la Fraternidade Teológica Latinoamericana. 


\section{Resumen:}

\section{Campo evangélico y sociedad civil: sobre los procesos de minoritización y el desplazamiento de matrices analíticas}

El presente artículo tiene por objetivo abrir algunos debates en torno a las mutaciones de la incidencia política de grupos evangélicos, a partir de la resignificación de algunos conceptos-eje, como los de espacio público, identidad religiosa y los nuevos escenarios de la relación con la sociedad civil, especialmente en términos globales. Desde este marco, el concepto de minoritización llevará a precisar las dinámicas políticas del campo evangélico dentro de este escenario, para luego utilizar como ejemplo los actuales procesos de auto-comprensión evangélica desde el uso de la llamada "agenda valórica” y el lugar de creciente visibilización que los evangélicos están teniendo dentro del sistema interamericano y otros proyectos de alcance regional.

Palabras clave: Sociedad civil; Campo evangélico; Minoritización; Espacio público; Sistema interamericano

\section{Abstract:}

\section{Evangelical field and civil society: on the processes of minorization and the displacement of analitic matrix}

The purpose of this article is to open some debates about the changes in the political incidence of evangelical groups, based on the resignification of some core concepts, such as those of public space, religious identity and the new scenarios of the relationship with the civil society, especially in global terms. From this framework, the concept of minorization will lead to specify the political dynamics of the evangelical field within this scenario, then use as an example the current processes of evangelical selfunderstanding from the use of the so-called "value agenda" and the place of increasing visibility that evangelical groups are having within the inter-American system and other regional projects.

Keywords: Civil society; Evangelical field; Minoritization; Public space; InterAmerican system 